\title{
NeuroRAD 2010: The German Society of Neuroradiology Has Passed the Test
}

\author{
Erich Hofmann
}

Published online: 4 December 2010

(C) Urban \& Vogel 2010

On October 07-09, NeuroRAD 2010, the $45^{\text {th }}$ annual meeting of the German Society of Neuroradiology (Deutsche Gesellschaft für Neuroradiologie, DGNR), took place in Cologne. It was the second time that the congress was held in the new big format which had proved so successful the year before. Unlike the pioneers in 2009, the organizers of this year's meeting, led by the congress president Professor Erich Hofmann, Head of Neuroradiology, Klinikum Fulda, had to face specific challenges, namely two high-ranking competitive congresses that were expected to attract many participants. Therefore, the focus of NeuroRAD 2010 was put on education since in 2009 many participants had expressed their great interest in continuing training. The topics chosen were aimed at addressing a wide public: Neurooncology, neurodegenerative diseases, contrast media, skull base, vertigo and tinnitus. Preceding the meeting, a well-frequented press conference addressed additional topics, e.g. stroke treatment, dementia, functional MRI and latest developments of computed tomography.

In NeuroRAD 2010, a new category of education was introduced: Fit for Neuroradiology (FFN) which specifically appealed to trainees in the field of neuroradiology. Attendants had the chance to actively participate in the session using a newly-introduced tele dialogue (TED) system. FFN and the entertaining TED poll at the first go-off turned to become favourites of the participants and proved to become a great success which should be continued.

In the interest of attracting broad interest in our topics, specific neurointervational issues were deliberately put aside

Prof. Dr. E. Hofmann $(\bowtie)$

Fulda, Germany

e-mail: EHofmann.RAZ@klinikum-fulda.de in the scientific and educational programme. Yet, a total of five industry-sponsored satellite symposia more than satisfied the interventional community as well.

Like in 2009, an attractive education programme for technicians attracted hundreds of spectators. Many of the lectures were given by heads of departments which underlines the apprehension of well-trained technicians as important co-workers.

The highlight of the congress, beyond doubt, was the keynote lecture given by Professor Willi Kalender, head of the Chair of Medical Physics, Friedrich-Alexander-Universität Erlangen-Nürnberg. At the meeting, Kalender was awarded the Ziedses des Plantes Medal by the president of the DGNR, Professor Rüdiger von Kummer, for his achievement in the development of computed tomography (Fig. 1). After a long interval of 15 years it had been the

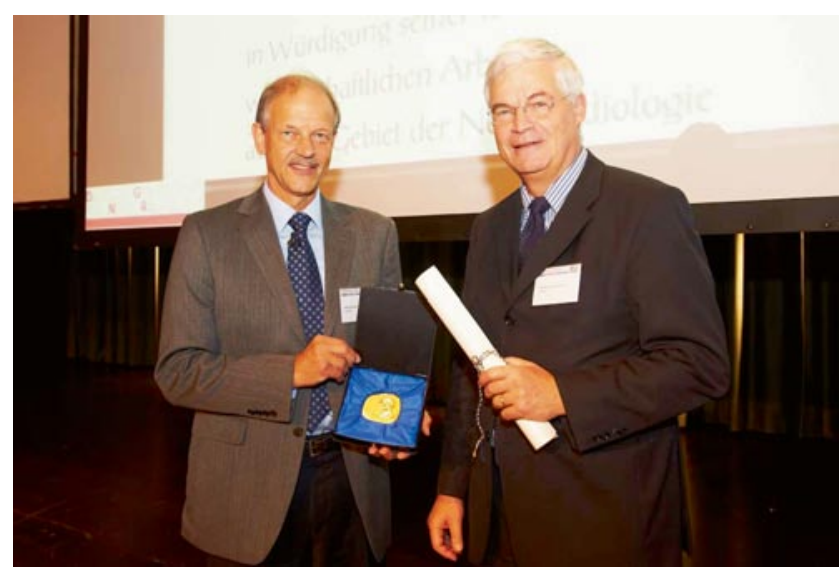

Fig. 1 Prof. Willi Kalender, laureate and holder of the Ziedses des Plantes Medal, Prof. von Kummer (left to right). With kind permission from Thieme 
first time that the DGNR resumed awarding its top-ranking honour.

More than 1200 participants, among them 350 radiography technicians, flocked into the Gürzenich, Cologne's famous convention hall. NeuroRAD has stood its test as the biggest meeting of neuroradiologists in Europe.

Prof. Dr. Erich Hofmann

President of NeuroRAD 2010 